\title{
THE ANATOMY OF SLEEP
}

The ebb and flow of neurotransmitters switches our brains between sleep and wakefulness in carefully regulated cycles. By Mark Peplow.



(1) UPPER PONS (2) thalamus (3) cerebral cortex (4) hypothalamus (6) Ventrolateral PReoptic nUCLEUS (VlPO)
7 SUPRACHIASMATIC NUCLEUS (SCN)

(5) Lateral hYPothalamus

8 PINEal gland 


\section{THE PHASES OF SLEEP}

In a typical eight-hour sleep, the brain moves through different stages of electrical activity in repeating cycles that last about 90 minutes. Rapid eye movement (REM) sleep is linked to distinctive electrical activity in the brain, and is often associated with dreaming.



\section{THE DECLINE OF SLEEP}

After a childhood filled with blissful slumber adulthood brings a decline in the quality and quantity of sleep.

Awake Slow wave sleep REM

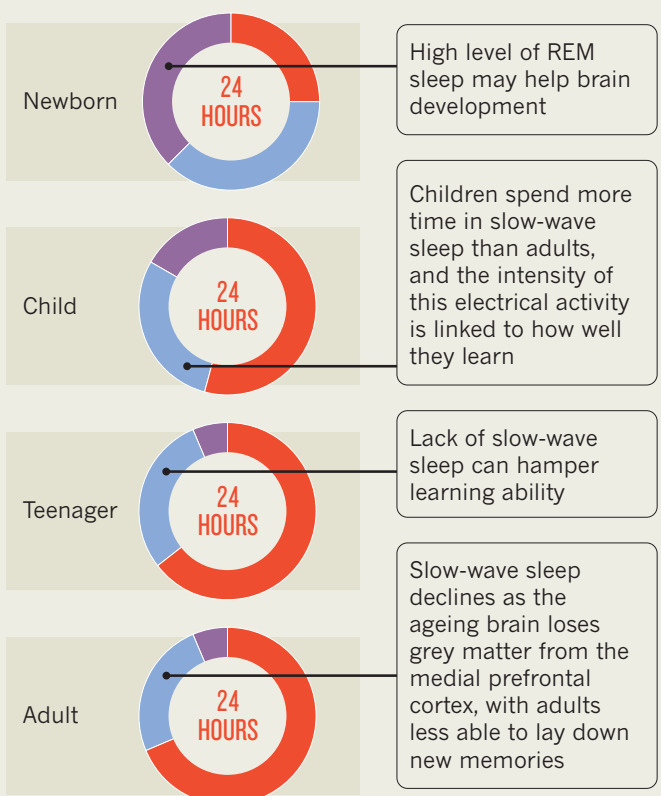

\section{THE DRUGS OF SLEEP}

The most widely used insomnia drugs promote sleep by improving the binding of $\gamma$-aminobutyric acid (GABA) to chloride ions released by the ventrolateral preoptic nucleus (VLPO) to suppress the ascending arousal system.

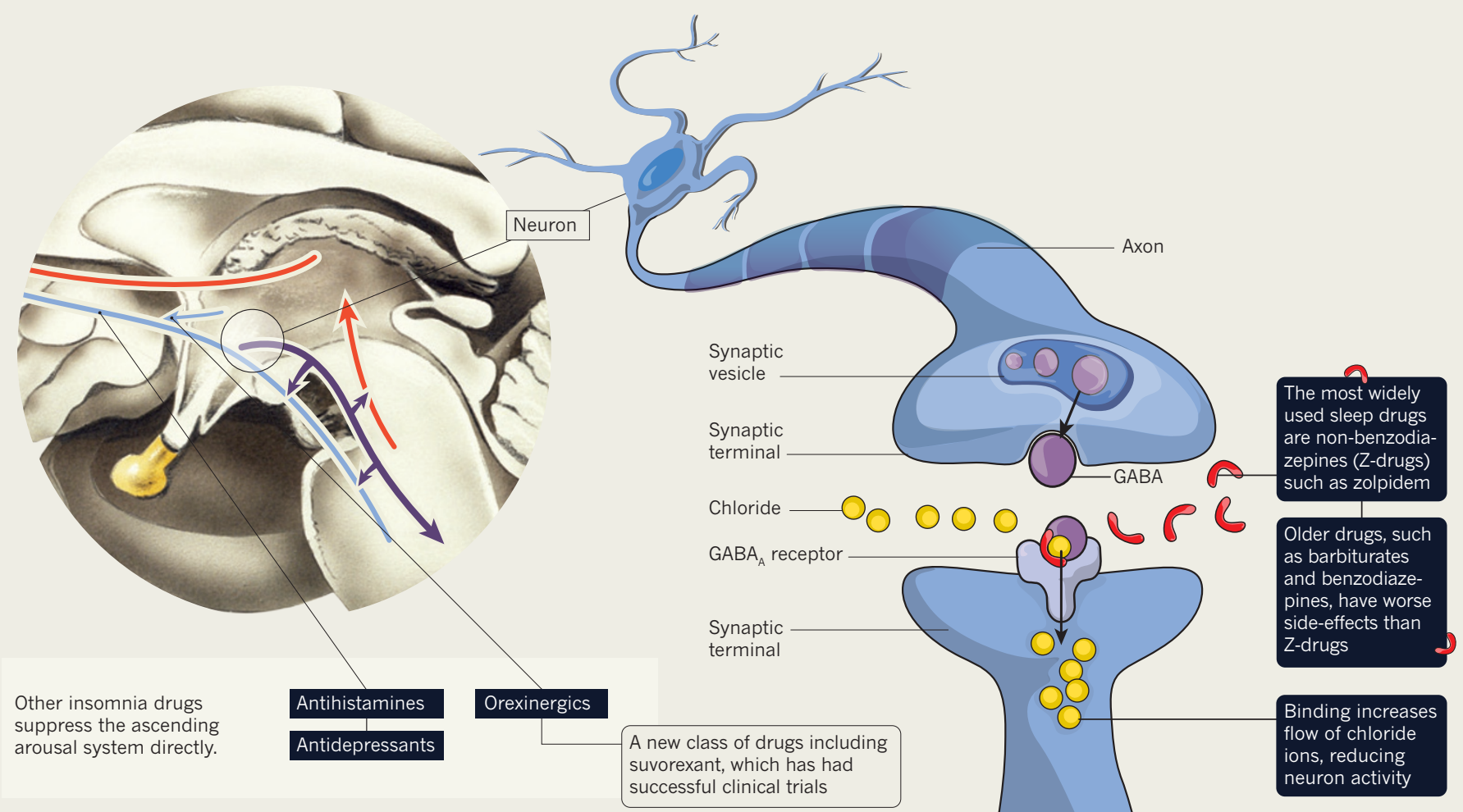

